\title{
Desenvolvimento e Escalas de Conflito Ambiental: o caso do Complexo Logístico-Industrial do Porto do Açu em São João da Barra (RJ)
}

\author{
Suyá Quintslr*
}

\begin{abstract}
RESUMO
Este artigo tem o objetivo de discutir o Complexo Logístico-Industrial do Porto do Açu (CLIPA) a partir de três eixos principais. Em primeiro lugar, enfoca o contexto de reposicionamento do Brasil na divisão internacional do trabalho como exportador de commodities primárias, que condicionou a aprovação, em 2013, de um novo marco regulatório com o objetivo de ampliação dos investimentos em infraestrutura portuária. Em segundo lugar, focaliza as alterações territoriais promovidas pela instalação do porto e os conflitos ambientais decorrentes de sua incompatibilidade com outros usos do território, em especial pesca artesanal e agricultura. Por fim, são avaliadas as características do empreendimento à luz da estrutura econômica e trajetória de ascensão e queda do grupo controlador, problematizando sua transferência a um fundo de investimentos estrangeiro. Nesse debate, o porto é compreendido como uma "janela" que unifica os três eixos, permitindo uma abordagem multiescalar centrada no Estado e no empreendedor, na intensificação dos conflitos envolvendo a apropriação dos recursos ambientais no território e no processo de acumulação por espoliação no Brasil contemporâneo.
\end{abstract}

Palavras-chave: Porto do Açu; conflito ambiental; desenvolvimento; acumulação por espoliação

\begin{abstract}
This paper aims at discussing the Açu Port Logistics and Industrial Complex (CLIPA) grounded on three major axes. Firstly, it focuses on the context of repositioning of Brazil within the international division of labor as a primary commodities exporter. Such context influenced the approval of a new regulatory framework for port industry in 2013, intended to increase investments in port infrastructure. In the second place, port-driven territorial transformations and environmental conflicts are highlighted, centered on the struggles over alternative uses of the territory, mainly artisanal fishing and agriculture. At last, the project is assessed in the light of the controlling group's economic structure and its ascending and descending pathway, questioning CLIPA's recent transfer to a foreign investment fund. In this debate, the port is understood as a "window" that unifies all three axes, allowing a multiscale approach related to the state and the entrepreneur, the rise of territorial conflicts involving
\end{abstract}

\footnotetext{
* Doutoranda do Programa de Pós-graduaçaõ em Planejamento Urbano e Regional (IPPUR/UFRJ). suya_q@yahoo.com.br
} 
appropriation of environmental resources and the process of accumulation by dispossession in contemporary Brazil.

Keywords: Açu Port; environmental conflict; development; accumulation by dispossession Introdução

Um levantamento inicial da produção acadêmica sobre a questão portuária indica a existência de estudos que abordam os portos sob óticas distintas: em primeiro lugar, é possível identificar, nas ciências naturais, estudos sobre os impactos de sua construção e operação sobre os ecossistemas locais; em segundo lugar, há estudos no campo da Geografia que abordam os portos ora como estruturas logísticas estruturantes do território, ora como nós das cadeias de transporte global. Vale destacar também estudos de caráter interdisciplinar sobre os conflitos ambientais que contrapõem comunidades locais e os responsáveis pelos empreendimentos.

Apesar da existência destes estudos interdisciplinares, percebe-se que eles, ao tratarem a dimensão local dos conflitos, tendem a negligenciar uma abordagem mais sistêmica da questão portuária como parte fundamental da circulação global de mercadorias, bem como a dimensão político-institucional envolvida na implantação de tais empreendimentos.

Considerando esta lacuna e o debate teórico sobre escalas empreendido no campo da Geografia Crítica, propõe-se conceber o grande empreendimento portuário de São João da Barra como uma "janela" entre as escalas local, nacional e global, mediatizando os conflitos ambientais locais, de um lado; um projeto de reconfiguração da posição do Brasil nas relações internacionais, de outro; e, finalmente, os interesses do capital transnacional e estratégias corporativas associadas.

\section{Reflexões sobre o modelo de desenvolvimento brasileiro}

A última década foi marcada na América Latina pelo surgimento de estratégias de desenvolvimento que vêm sendo classificadas por diversos autores como um "novo desenvolvimentismo" (Bresser-Pereira, 2006; Sicsú et al., 2007), em relação à implementação do ideário neoliberal da década de 1990. Ainda que não exista consenso sobre o sentido exato desta nova estratégia, pode-se dizer que ela busca o fortalecimento do Estado e se fundamenta na crença de que o crescimento econômico a taxas elevadas e contínuas é condição necessária, se bem que não suficiente, para a redução das desigualdades sociais no país (Sicsú et al., 2007). A qualificação de "novo" se justifica na medida em que se diferencia do 
desenvolvimentismo surgido na década de 1930 e reforçado no pós-guerra. A estratégia atual busca o fortalecimento do Estado e do mercado como instâncias complementares e fundamentais ao crescimento e, diferentemente do antigo desenvolvimentismo, não se baseia em políticas protecionistas e na busca pela independência do mercado internacional. Ao contrário, objetiva aumentar a competitividade da indústria e melhorar a inserção externa do país.

Como expresso no nome escolhido pelo governo federal para designar seus planos de desenvolvimento - Plano de Aceleração do Crescimento $^{1}{ }^{-}$, admite-se a centralidade do crescimento econômico, que continua sendo representado como fator primordial para a redução das desigualdades sociais e regionais. Cabe ressaltar, entretanto, que diversos autores contestam esta visão hegemônica. Para Brandão (2009), tal visão - por ele denominada "elaboração conservadora de desenvolvimento" - pressupõe um tipo ideal de capitalismo que deve ser perseguido pelas nações não desenvolvidas. Considera-se, assim, a existência de "um caminho natural, linear e mecânico de espraiamento e difusão de modernização capitalista" (ibid., p. 156), cabendo aos Estados concentrar-se em eliminar os entraves (ou gargalos) ao processo.

Segundo a estratégia de desenvolvimento adotada, o crescimento a elevadas taxas pressupõe o aumento das exportações, bem como da competitividade da indústria nacional. Entretanto, tal aumento de competitividade não se verifica e é possível perceber que volta a ganhar importância para a economia nacional a exportação de produtos primários e semielaborados (Brandão, 2010; De Negri e Alvarenga, 2011), constituindo um processo de reprimarização econômica. Dados do Ministério do Desenvolvimento, Indústria e Comércio Exterior (MDIC) sobre exportação por setores industriais segundo intensidade tecnológica ${ }^{2}$ indicam uma clara tendência de expansão relativa dos produtos não industriais. Entre 2001 e 2011, sua participação nas exportações passou de $18 \%$ para $40 \%$. Soja e minério de ferro estiveram entre as principais commodities exportadas em 2010 (MDIC, 2013). O incentivo à exportação de tais produtos, entretanto, não considera os impactos ambientais e conflitos decorrentes da incorporação de novas áreas, característica tanto da atividade de plantio da

\footnotetext{
${ }^{1}$ Lançado no início do segundo mandato do presidente Lula (2007) e posteriormente incorporado ao PPA 20082011, incluía ações e metas que buscavam acelerar o crescimento econômico através de "um amplo conjunto de investimentos em infraestrutura e um grupo de medidas de incentivo e facilitação do investimento privado" (GOVERNO FEDERAL, s/d: 3). Tais investimentos tinham como objetivo "superar os gargalos da economia e estimular o aumento da produtividade e a diminuição das desigualdades regionais e sociais" (Ibid.).

${ }^{2}$ A classificação utilizada pelo MDIC segue orientação de estudo da Organização para Cooperação e Desenvolvimento Econômico (OCDE), que diferencia os setores industriais segundo o investimento em pesquisa e desenvolvimento tecnológico.
} 
soja, que avança sobre a fronteira amazônica, quanto da mineração, que avança sobre terras indígenas e áreas de proteção integral (ISA, 2013).

Neste cenário de crescimento das exportações de commodities e de consenso em relação à necessidade de crescimento do país, a superação dos 'gargalos' para a ampliação do produto nacional diz respeito, sobretudo, ao enfrentamento dos problemas de infraestrutura, garantindo a circulação de mercadorias e, em especial, sua exportação. ${ }^{3}$ Considerando a relevância do transporte aquaviário nas exportações brasileiras - o segmento foi responsável por 96\% do volume exportado em 2010 (ANTAQ, 2011) -, o governo busca, atualmente, reduzir os custos do frete marítimo e o tempo médio de carga e descarga de mercadorias. $\mathrm{Na}$ tentativa de alcançar tal objetivo através do aumento dos investimentos privados e da competitividade no setor, editou, em 2012, a Medida Provisória n 595/2012 ("MP dos Portos"), propondo um novo marco regulatório para o setor portuário. A medida foi objeto de inúmeras emendas e gerou intenso conflito político, sendo aprovada pelo Congresso Nacional em maio de 2013. O texto ainda sofreu vetos da Presidência da República antes de ser promulgado como Lei $\mathrm{n}^{\mathrm{o}} 12.815 / 2013$. $^{4}$

\section{A relação entre porto e território}

Em relação aos investimentos previstos no setor portuário, cabe ressaltar, como advertem Monié e Vidal (2006:977), que o porto "não pode ser pensado apenas do ponto de vista técnico e operacional. Ele não é apenas um corredor, ele é mais: um instrumento a serviço de um projeto de desenvolvimento". Ao que parece, segundo os dados apresentados, a melhoria da infraestrutura portuária no Brasil está a serviço de um modelo de desenvolvimento que se baseia no reposicionamento do país na Divisão Internacional do Trabalho (DIT) como exportador de produtos primários. ${ }^{5}$

\footnotetext{
${ }^{3}$ Problemas recentes no escoamento da produção da soja - considerados como fricções ou constrangimentos (Brandão, 2009) a serem superados para abrir caminho ao 'desenvolvimento' - vêm preocupando a Associação de Comércio Exterior do Brasil (AEB), que previa safra recorde do grão em 2013 de cerca de 83 milhões de toneladas $(O$ Globo, 2013). A previsão era de que o "complexo da soja" (que inclui o grão, o óleo e o farelo de soja) ultrapassasse as exportações de minério de ferro no mesmo ano (chegando a US\$ 32,5 bilhões, contra US\$ 30 bilhões do minério de ferro). Segundo o presidente do Sindicato das Agências de Navegação Marítima de São Paulo (Sindamar), "não adianta ter supersafra, se as empresas estão perdendo na ponta, sem conseguir escoar a produção" (O Globo, 2013).

${ }^{4}$ Com a modificação na legislação portuária, o governo busca atrair investimentos da iniciativa privada no setor (com previsão de R \$ 54,2 bilhões até 2017) e licitar 159 terminais marítimos (Exame, 2013a).

${ }^{5}$ Em relação ao Complexo Logístico-Industrial do Porto do Açu, por exemplo, Martins (2013) considera que este seja um empreendimento emblemático do modelo exportador de produtos primários e semielaborados. Segundo Pedlowski (2012), o investimento no Porto de São João da Barra/RJ parte da aposta na exportação de
} 
Frente à previsão de aceleração dos investimentos em terminais portuários no país e às alterações no território promovidas pela instalação de um porto, torna-se de suma importância compreender em maiores detalhes os impactos desta atividade sobre o meio ambiente e sobre as populações residentes nas áreas a serem transformadas. A respeito dessas mudanças de ordem estrutural, Cunha (2006:1024) afirma que:

Os portos são elos das cadeias logísticas que integram fluxos de transporte de mercadorias entre duas regiões diferentes, gerando influências que vão muito além de seus locais de instalação. Barragán Muñoz (1995) diz que os portos são infraestruturas estruturantes, determinando a dinâmica territorial a sua volta, condicionando a construção de estradas, ou a configuração das malhas urbanas.

Além das grandes alterações territoriais decorrentes de seus processos de implantação e operação, há estudos apontando a ocorrência de inúmeros conflitos ambientais entre a atividade portuária e outros usos do território e dos recursos ambientais. Tais conflitos dizem respeito, em especial, à demanda por espaço para construção de pátios de cargas, às ações de dragagem e à sobreposição de canais dos portos às rotas de pesca artesanal. Além destes, é possível que ocorram episódios de poluição e acidentes ambientais decorrentes de atividades operacionais, com consequências para as comunidades vizinhas (Cunha, 2006). A dimensão dos impactos, entretanto, dependerá do tipo de porto em questão e da carga movimentada.

Segundo Cunha (2006), a demanda por espaço dos empreendimentos portuários aumentou, principalmente, em decorrência da introdução do uso de contêineres para o transporte de carga, o que também condiciona a profundidade dos canais. Nesse sentido, os empreendimentos portuários que incluem complexos logístico-industriais podem envolver alterações territoriais de dimensão ampliada, uma vez que há maior demanda por espaço e as atividades industriais a eles associadas tendem a constituir fonte adicional de degradação do ambiente e de conflitos ambientais. O Complexo Logístico-Industrial do Porto do Açu (CLIPA), em instalação, e o Complexo Industrial Portuário de Suape, operando com mais de 100 empresas e outras 50 em fase de instalação (SUAPE, 2012), são exemplos deste processo.

Perez e Gonçalves (2012), em artigo sobre os conflitos territoriais envolvendo a ampliação de Suape, nos municípios de Ipojuca e Santo Agostinho (PE), demonstram como os conflitos vêm se intensificando com o desenvolvimento do complexo desde a década de

minério de ferro para a China, tendo sido a localização do porto escolhida, entre outros motivos, em função da proximidade do Quadrilátero Ferrífero, em Minas Gerais, e dos campos de petróleo da Bacia de Campos. 
1970. Segundo os autores, os conflitos, que envolvem tanto a atividade portuária quanto a atividade industrial, intensificaram-se a partir da década de 1990, coincidindo com o processo de modernização dos portos ${ }^{6}$ e com o início da circulação de produtos através de contêineres. Como exemplo, vale citar o desalojamento de 480 famílias para a implantação de indústrias petroquímicas; as comunidades impactadas pela instalação de Estação de Tratamento de Esgoto, fruto da recente urbanização da área; e os prejuízos sofridos por pescadores artesanais. Em relação à pesca, os impactos decorrem tanto da destruição do manguezal, em virtude da construção de um estaleiro, quanto das dragagens necessárias à operação dos terminais. Somam-se, a estes, conflitos oriundos das restrições de uso dos recursos impostas por uma Unidade de Conservação (UC) que faz parte do plano diretor de Suape (Perez; Gonçalves, 2012).

Outros conflitos ambientais envolvendo a atividade portuária são descritos por Zborowski e Loureiro (2008), no caso do Porto de Itaguaí (RJ), e Cunha (2003), para o Porto de São Sebastião (SP). Casto e Almeida (2012) narram, ainda, conflitos em diversos portos em decorrência de obras de dragagem.

Além das transformações territoriais e dos conflitos locais envolvendo os portos, o aumento dos investimentos no setor remete a questões que transcendem a escala local. Faz-se necessário, portanto, uma revisão do debate teórico acerca de escalas geográficas para a compreensão do papel da infraestrutura portuária na articulação dos espaços e fluxos da economia contemporânea.

\section{Contribuições do debate teórico acerca das escalas de ação e de análise}

Castro, ao problematizar o conceito de escala, conclui que, nas últimas décadas, sua reelaboração "começa a ir além de uma medida de proporção da representação geográfica do território, ganhando novos contornos para expressar a representação dos diferentes modos de apreensão do real" (2008:118). Nesse sentido, no que concerne ao problema da seleção das escalas de análise, a autora afirma que qualquer escolha define um recorte da realidade, em detrimento de outras dimensões escalares, potencialmente reveladoras de aspectos relevantes do mesmo fenômeno.

Neste trabalho, concebe-se a escala enquanto construção social conflitiva (Swyngedouw, 2004; Brandão, 2009). Nesse sentido, cabe ressaltar a distinção da escala

\footnotetext{
${ }^{6} \mathrm{O}$ marco jurídico-institucional da referida modernização se dá com a Lei no 8630 de 1993.
} 
geográfica enquanto "categoria e unidade de análise" e enquanto "categoria da prática", como proposta por Brandão, a partir do pensamento de Adam Moore. Segundo o autor, a escala enquanto "categoria da prática" demarca o campo das lutas sociais, sendo um "locus de embates e enfrentamentos [que] não pode ser definido em si, mas apenas em relação com o outro" (Brandão, 2009:172).

Vainer (2001), por sua vez, alega que atualmente o debate sobre as escalas da ação política encontra-se dominado pela oposição local versus global. Segundo o autor, os "globalistas" defendem como prioritária para ação a escala global e consideram o Estado nacional cada vez mais impotente para fazer frente aos desafios colocados pela globalização. Em oposição, mas também desabilitando o papel da escala nacional, os "localistas" defendem o lugar como locus prioritário de ação e alegam a importância de engajar as cidades e os lugares na competição global. Segundo essa visão, cresce, no mundo globalizado, a importância do local, devido à "diminuição dos custos de transporte e a consequente redução das barreiras para o movimento de bens, pessoas, moedas e informações” (Harvey, 2005:179), ocasionando uma competição entre locais pela atração de capitais. Processos de desregulamentação, renúncias fiscais, facilitação de aquisição de terrenos (Fernandes, 2001; Harvey, 2005; Vainer, 2007) fariam parte da estratégia do novo empreendedorismo urbano (Harvey, 2005) ou "neo-localismo competitivo e empreendedorista" (Vainer, 2007).

Swyngedouw (2004) utiliza o conceito de glocalização para ressaltar aspectos considerados por ele cruciais no capitalismo contemporâneo, referindo-se:

[...] (i) à reestruturação institucional contestada da escala nacional, tanto de forma ascendente para os níveis supranacional ou global, quanto descendente para a escala do corpo do indivíduo ou para configurações locais, urbanas ou regionais e (ii) às estratégias de localização global de formas-chave de capital industrial, de serviços e financeiro. (Swyngedouw, 2004:37) ${ }^{7}$

Na mesma perspectiva, Fernandes considera a existência de um duplo movimento contraditório: "um de globalização da atividade econômica e da decisão política e outro de descentralização da organização da vida cotidiana necessária ao movimento anterior" (Fernandes, 2001:31). Tal descentralização presta-se não apenas à atração de investimentos, mas, igualmente, reforça a posição das "elites de crescimento local”. Assim, as coalizões de crescimento, formadas pela associação do poder público local às elites locais tradicionais, possibilitam a produção do ambiente jurídico-institucional necessário à viabilização de seus

\footnotetext{
${ }^{7}$ Todas as citações de trabalhos publicados em inglês apresentam tradução livre da própria autora.
} 
objetivos e projetos. A autora afirma, ainda, que o poder público local é um dos principais agentes do processo, proporcionando as condições vantajosas para o capital privado e assumindo os riscos das atividades.

Outros autores, em perspectiva um pouco distinta, reiteram a importância da escala nacional (Weiss, 1997; Dicken et al., 2001; Vainer, 2001). Weiss (1997) adverte que aqueles que menosprezam a importância dos Estados nacionais desconsideram sua capacidade de adaptação, as diferenças entre eles e a continuidade da importância de seu poder no ambiente internacional. Dicken et al. (2001), ao proporem uma metodologia de redes para análise da economia global, consideram que múltiplas escalas de análise e distintos loci institucionais devem ser considerados. Para os autores, "torna-se sem sentido falar de processos locais versus globais, como na maior parte da literatura 'global-local'; ao contrário, dever-se-ia pensar em termos de rede de agentes [...] agindo ao longo de várias distâncias e através de diversos intermediários" (ibid., p. 95).

Para além do debate acerca das escalas prioritárias de análise e ação política, o que parece ser relativamente consensual é o fato de que as escalas estão sendo constantemente construídas e reconstruídas através dos processos sociais e que o capitalismo contemporâneo apresenta novos desafios aos agentes nas diversas escalas nas quais operam - local, regional, nacional e global.

A literatura também aborda a questão das implicações das redefinições escalares para os movimentos de resistência. No processo sempre conflituoso de definição e redefinição de escalas (reescalonamentos), a geometria de poder social também pode sofrer alterações. Nesse contexto, sugere-se que as lutas emancipatórias devem ser multiescalares (Brandão, 2009), devendo os movimentos de resistência realizar articulações com outros movimentos, sejam alianças horizontais ou através de diferentes escalas, que permitam transcender particularismos locais (Swyngedouw, 2004; Harvey, 1996 apud Kurtz, 2003).

Kurtz (2003), em artigo que discute como as lutas por justiça ambiental nos EUA criam e renegociam escalas geográficas, propõe os conceitos de enquadramentos (scale frames) e contraenquadramentos de escala (conter-scale frames), sendo o primeiro um tipo de quadro de ação coletiva que se baseia na articulação de relações sociais que se organizam em escalas variadas, diferenciando a escala na qual um problema é experienciado daquela na qual ele pode ser politicamente abordado ou resolvido. Contraenquadramentos de escala, por outro lado, são estratégias discursivas direcionadas a contestar os enquadramentos de escala. Estes são redefinidos e reformulados no processo de embate político, tanto em resposta a 
contradições internas quanto em resposta ao emprego de contraenquadramentos de escalas. Segundo a autora, o próprio conceito de justiça ambiental precipita uma política de escala, uma vez que o problema local (no caso do trabalho citado, a poluição) dificilmente pode ser resolvido nesta escala, pois que deriva de relações políticas e econômicas que vão muito além dela.

\section{O Grupo EBX e o Complexo Logístico-Industrial do Porto do Açu (CLIPA)}

O Complexo Logístico-Industrial do Porto do Açu (CLIPA) em São João da Barra, Estado do Rio de Janeiro, faz parte de uma série de investimentos propostos pelo grupo EBX, liderado pelo empresário brasileiro Eike Fuhrken Batista da Silva, ${ }^{8}$ nas áreas de energia, petróleo e gás, mineração e logística.

O grupo EBX, no momento do licenciamento ambiental do complexo portuário, era composto pelas seguintes empresas: MMX (mineração); OGX (exploração de petróleo e gás); LLX (logística); MPX (energia); OSX (equipamentos e serviços para a indústria offshore de óleo e gás); além de empresas menores, tais como: REX (setor imobiliário); MDX (Barra Medical Center); Pink Fleet; Glória Palace Hotel; Restaurante Mr. Lan; e Rio Marina Glória (Ecologus, 2011).

Ao longo do ano de 2013, entretanto, as principais cotações acionárias em bolsas de valores das empresas do grupo sofreram fortes quedas e o empresário, que chegou a ser apontado pela revista Forbes como o sétimo homem mais rico do mundo, vendeu parte das ações de suas subsidiárias e deixou o controle de alguns empreendimentos em setores estratégicos da economia. Segundo a agência de notícias Reuters, os ativos da EBX, que chegaram a ser avaliados em U\$60 bilhões, valiam em agosto de 2013 menos de U\$5 bilhões (Reuters, 2013a).

Vale ressaltar que a valorização dos ativos da EBX se deu, em grande parte, devido à confiança depositada no empresário que, inicialmente, se beneficiou do boom das commodities da primeira década do século XXI. A confiança construída ao redor do empresário permitiu a este abrir o capital de suas empresas em bolsa, captando o volume recorde de recursos de U\$ 7,1 bilhões. Também tiveram grande importância nesse desenvolvimento os empréstimos do Banco Nacional de Desenvolvimento Econômico e

\footnotetext{
${ }^{8}$ Eike Batista é filho do engenheiro Eliezer Batista que foi presidente da Companhia Vale do Rio Doce por duas vezes e ministro de Minas e Energia durante o governo João Goulart (1961-1964).
} 
Social (BNDES), cujas operações com o grupo, segundo a revista Exame (2013b), chegam a $\mathrm{R}$ \$ 10,4 bilhões. Quando se tornou evidente que suas operações não apresentariam os resultados esperados, o Grupo EBX vendeu partes dos ativos empresariais, deixando o controle de algumas empresas, numa tentativa de evitar a falência.

Ainda que os primeiros indícios de crise viessem ocorrendo desde 2011, o desmantelamento do "império" sobreveio no primeiro semestre de 2013, com a venda de 24,5\% do capital da MPX para o conglomerado energético alemão E.ON SE, que, passando a deter $36,2 \%$ do capital da joint venture, assumiu seu controle acionário - Eike Batista ficou com uma parcela de 23,9\% das ações. No mês de novembro do mesmo ano, a MPX alterou sua denominação para ENEVA S.A.

Em agosto, a MMX Mineração S.A. colocou à venda, entre outros ativos, a mina de minério de ferro em Corumbá (MT) (Reuters, 2013b). No mesmo mês, ocorreu a venda de ações da LLX Logística S.A. para a EIG Global Energy Partners, LLC - uma empresa norteamericana de gestão de investimentos, que atua nas áreas de energia e infraestrutura relacionada -, a qual se tornou controladora da empresa de logística responsável pela implantação do CLIPA. Uma condição para a realização da transação foi a renegociação dos empréstimos com o BNDES e o Bradesco S.A.. Posteriormente, novas transações fizeram com que a EIG se tornasse detentora de $53 \%$ das ações da empresa, atualmente Prumo Logística Global (Folha de São Paulo, 2013; Reuters, 2013c).

No mês seguinte, vendas em bloco de ações da OGX reduziram a participação de Eike Batista a cerca de 52\%. A empresa, mesmo continuando sob controle da EBX, alterou sua denominação posteriormente para OGPar (Reuters, 2013d). Finalmente, em outubro, o controle sobre o Porto Sudeste, ${ }^{9}$ desmembrado da MMX Mineração S.A., foi transferido para duas empresas estrangeiras: a trading company holandesa Trafigura Beheer BV, uma das maiores do mundo nas áreas de metais e energia; e a Mubadala Development Co., um fundo de investimento soberano do governo de Abu Dhabi, Emirados Árabes Unidos. As empresas detêm, atualmente, $65 \%$ do capital do porto.

O CLIPA, tal como foi planejado, pode ser compreendido como o eixo principal dos investimentos previstos e realizados do grupo EBX, em função de suas dimensões - "maior porto da América Latina” (Prumo Logística, 2014a) - e, sobretudo, de sua capacidade de integração e conexão dos demais projetos, tornando-os viáveis economicamente,

\footnotetext{
${ }^{9}$ O Porto Sudeste é um porto projetado para escoamento de minério de ferro localizado em Itaguaí, RJ.
} 
particularmente no que diz respeito aos canais de escoamento interno e de exportação de minério de ferro e de petróleo.

O complexo, que é formado pelo Superporto do Açu e pelo Distrito Industrial de São João da Barra (DISJB), vem sendo instalado desde 2007, na região norte do Estado do Rio de Janeiro, no $5^{\circ}$ Distrito de São João da Barra. A infraestrutura portuária se encontra, atualmente, sob controle da Prumo Logística Global, liderada pela EIG. ${ }^{10}$ Por sua vez, o DISJB é formalmente responsabilidade da Companhia de Desenvolvimento Industrial do Estado do Rio de Janeiro (CODIN). Entretanto, como esclarece o Relatório de Impacto Ambiental (RIMA) do empreendimento:

Foi firmado memorando de entendimentos entre o governo do Estado do Rio de Janeiro e a empresa LLX Açu Operações Portuárias S/A, cabendo a esta última implantar as infraestruturas de uso comum do Distrito Industrial de São João da Barra, sendo também responsável pelo licenciamento ambiental do empreendimento. Assim, são empreendedores do DISJB a LLX Açu e a CODIN. (ECOLOGUS/AGRAR, s/d:03)

O Superporto do Açu é um complexo portuário composto por dois terminais: T1 (offshore) e T2 (onshore) (Prumo Logística, 2014a). Segundo informações previamente veiculadas pela LLX, a previsão original de movimentação era de até 350 milhões de toneladas de carga por ano entre exportações e importações, sendo a maior parte deste volume composto por petróleo e seus derivados (LLX, 2013). Outro destaque do projeto é a construção de um mineroduto que trará minério de ferro de jazidas localizadas a $525 \mathrm{~km}$ de distância, desde Conceição do Mato Dentro (MG), cuja propriedade foi transferida para a britânica Anglo American. O projeto de exportação de produtos primários ou semielaborados pode ser verificado pela estrutura do empreendimento, descrita no site da empresa:

O T1 contará com nove berços para atracação de navios: quatro dedicados ao minério de ferro, que poderão movimentar até 100 milhões de toneladas por ano, e cinco berços para movimentação de até 1,2 milhão de barris de petróleo por dia (bpd). [...] O T2 contará com mais de 13 quilômetros de cais, onde serão movimentados ferro gusa, carvão mineral, veículos, granéis líquidos e sólidos, carga geral e petróleo. (Prumo Logística, 2014a)

O projeto do porto, considerado o maior da América Latina, terá capacidade para receber navios modernos, devido à grande profundidade (que poderá chegar a 25m), e até 47

\footnotetext{
${ }^{10}$ Inicialmente o projeto foi proposto pela LLX Açu Operações Portuárias S.A., então subsidiária da LLX Logística S.A., do grupo EBX.
} 
embarcações em seus 17 km de píeres. Em síntese, nos próximos anos, é esperada intensa movimentação de navios de grande porte na região.

Em relação ao DISJB, a Prumo Logística (2014b) informa que ele ocupará uma área de 7.036 hectares, onde está projetada a instalação de diferentes unidades industriais. Primeiramente, indústrias de apoio offshore, como a National Oilwell Varco (NOV), líder mundial no fornecimento de componentes mecânicos para sondas de perfuração; a Technip Brasil, com a implantação de uma unidade de tubos flexíveis de R \$ 650 milhões; a InterMoor, com unidade de apoio logístico e serviços especializados; e a BP Marine, com a construção de um terminal de distribuição de combustíveis marítimos.

Devem compor também o polo, indústrias metalomecânicas, como a Wärtsilä, líder no fornecimento de motores e serviços para navios e termelétricas; a GE, com foco em serviços de infraestrutura nas áreas de petróleo e gás e geração de energia; e a Vallourec, que pretende implantar uma base logística de armazenagem e fornecimento just in time de tubos e serviços especializados.

São relevantes, ainda, os investimentos da Edison Chouest Offshore (ECO) em uma base de apoio logístico e estaleiro de reparos navais, da ordem de $\mathrm{R} \$ 950$ milhões, e o projeto do estaleiro da OSX (Unidade de Construção Naval do Açu); assim como os da Eneva em um complexo termoelétrico movido a carvão térmico e a gás natural; além de plantas de pelotização de minério de ferro e bases de estocagem para granéis líquidos e para tratamento de petróleo (Prumo Logística, 2014a).

Conforme o RIMA do empreendimento, a instalação do DISJB afetará especialmente o "núcleo agrícola" do $5^{\circ}$ Distrito do município, onde existem 1.480 propriedades rurais, sendo a maior parte delas de pequeno e médio portes. A realização de levantamento fundiário indicou a existência de 581 famílias no perímetro delimitado pelo distrito que devem ter seus lotes desapropriados, sendo que em 389 deles se desenvolvem a agricultura familiar e a produção de alimentos, em especial quiabo, maxixe, pimentão, mandioca, abacaxi e coco anão (ECOLOGUS/AGRAR, s/d).

\section{Conflitos ambientais e acumulação por espoliação}

Tendo em vista a magnitude e o caráter do empreendimento e das empresas previstas, é possível inferir a ocorrência de conflitos ambientais em decorrência de sua instalação. Uma revisão dos trabalhos acadêmicos produzidos sobre o CLIPA apresenta os principais conflitos 
já em curso. Segundo esses estudos, tais conflitos se relacionam ao uso da terra (AGB, 2011; Freitas e Oliveira, 2012; Barreto e Quinto Jr, 2012; Martins, 2013), em especial devido ao processo de desapropriação de lotes rurais; e à pesca artesanal, devido às dragagens, ao botafora marítimo (local de descarte do material dragado) e às restrições ao trânsito de embarcações de pequeno porte nos locais de obras (Souza; Terra e Oliveira, 2009).

Outros impactos esperados da instalação do empreendimento são decorrentes do aumento populacional (Kury; Rezende e Pedlowski, 2010; Quinto Jr e Coutinho, 2011; Rangel e Quinto Jr, 2012) ${ }^{11}$ e da ocupação de áreas ambientalmente frágeis (Rangel e Quinto Jr, 2012). ${ }^{12}$ Além destes estudos acadêmicos, no final de 2013 foi produzido, no âmbito do Encontro de Intercâmbio das Comunidades em Resistência ao Projeto Minas-Rio, ${ }^{13}$ um amplo relatório intitulado "O projeto Minas-Rio e seus impactos socioambientais: olhares desde a perspectiva dos atingidos" (Barcelos, 2013) que reitera a ocorrência de tais conflitos.

O conflito pela terra foi o que assumiu maior proporção no $5^{\circ}$ Distrito de São João da Barra, havendo indício de irregularidades tanto na desapropriação das áreas pertencentes à CODIN (onde vem sendo instalado o DISJB) quanto naquelas adquiridas pelo grupo EBX, correspondentes às fazendas Saco d'Antas e Caruara. As áreas desapropriadas pela CODIN, com mais de 7 mil hectares, foram primeiramente declaradas de utilidade pública pelos decretos estaduais $n^{\circ}$ 41.584/08 e n 41.915/09 e há denúncias de problemas nas notificações dos agricultores e na negociação dos preços praticados nas indenizações, bem como do uso de violência nas desapropriações. Segundo o relatório supracitado (Barcelos, 2013):

No caso das áreas que estão sendo desapropriadas pela CODIN, os problemas envolvem a forma de notificação, erros de vistoria, subavaliação e assédio moral. A ASPRIM relata que as famílias têm sido intimidadas por agentes de segurança privada, contratados pela LLX, pela Polícia Militar do $8^{\circ}$ Batalhão de Campos e por ações criminosas, como o caso de agricultores que tiveram suas terras e lavouras invadidas e destruídas em pleno final de semana e no período noturno.

\footnotetext{
${ }^{11}$ Segundo os estudos mencionados, São João da Barra deverá ter um aumento populacional da ordem de $600 \%$ em 15 anos, passando sua população dos atuais 32.090 habitantes para cerca de 200 mil.

${ }^{12}$ Em relação à área de instalação do CLIPA, Rangel e Quinto Jr (2012) advertem para possíveis problemas na alteração do uso e ocupação da terra em virtude da área ter formação geológica recente e da fragilidade dos terrenos do Quaternário Costeiro, os quais possuem lençol freático aflorado, o que demandaria, segundo os autores, cautelosos estudos de macrodrenagem para evitar impactos indesejáveis.

${ }^{13}$ A articulação das comunidades impactadas em Minas Gerais e Rio de Janeiro pelo Projeto Minas-Rio pode ser compreendida como uma forma de reescalonamento dos movimentos de resistência, na tentativa de transcender a dimensão localizada dos problemas por eles enfrentados, como discutido no item 3 deste artigo. Entretanto, uma análise dos processos de reescalonamento da crítica social no que diz respeito ao CLIPA está além do escopo deste artigo.
} 
De acordo com o mesmo documento, as fazendas Saco d'Antas e Caruara vêm sendo desapropriadas para serem ocupadas pelas instalações portuárias e pela Reserva Particular do Patrimônio Natural (RPPN) de Caruara (inicialmente havia previsão de uma usina termelétrica, mas o projeto foi alterado). Assim, mesmo as compensações ambientais previstas pelo licenciamento do empreendimento, i.e., a criação de três unidades de conservação - Área de Proteção Ambiental de Grussaí, RPPN de Caruara e Parque Estadual do Açu - deverão impactar um grande número de propriedades rurais, em decorrência de mudanças nas regras de uso do solo que sua criação representa, sobretudo a do Parque Estadual do Açu, devido às regras mais rígidas desta categoria.

Como é possível inferir pela descrição acima, existem diversos conflitos relacionados à construção e operação do CLIPA no que diz respeito à apropriação dos recursos ambientais, os quais podem ser considerados conflitos ambientais, no sentido atribuído ao termo por Acselrad (2004). Segundo o autor:

[...] os conflitos ambientais são aqueles envolvendo grupos sociais com modos diferenciados de apropriação, uso e significação do território, tendo origem quando pelo menos um dos grupos tem a continuidade das formas de apropriação do meio [...] ameaçadas por impactos indesejáveis [...] decorrentes do exercício da prática de outros grupos. (Acselrad, 2004:26)

Assim, os conflitos entre pescadores, agricultores sujeitos a reassentamento e empreendedores ${ }^{14}$ podem ser considerados casos emblemáticos de conflitos ambientais, segundo o conceito apresentado. Não obstante estes representarem os conflitos mais evidentes decorrentes da atividade portuária, outros devem emergir da construção do complexo logístico-industrial na região. Conforme adverte Acselrad, "o conflito pode derivar da disputa por apropriação de uma mesma base de recursos ou de bases distintas mas interconectadas por interações ecossistêmicas mediadas pela atmosfera, pelo solo, pelas águas etc.” (ibid., p. 26).

Desta forma, é possível prever a eclosão de conflitos devido ao aumento da poluição atmosférica pelo grande número de indústrias a serem instaladas (e pelo caráter das mesmas) e conflitos, já denunciados pela população e por pesquisadores, relativos ao uso da água. Estes últimos foram ocasionados pela salinização do lençol freático que, além de tornar a água dos poços artesianos (forma de abastecimento predominante no local) imprópria para uso humano, prejudicou agricultores de áreas próximas à instalação do CLIPA que a utilizaram para

\footnotetext{
${ }^{14} \mathrm{O}$ conflito em São João da Barra envolve, além de pescadores artesanais e pequenos agricultores, outros agentes públicos (como o Governo do Estado do Rio de Janeiro, a CODIN, o Instituto Estadual do Ambiente INEA) e privados, como ASPRIM, ONGs, a Prumo Logística, associações profissionais (Associação de Geógrafos Brasileiros, AGB), entre outros.
} 
irrigação das lavouras, levando à perda da produção $(G 1,2013)$. Segundo o relatório produzido pelas comunidades impactadas anteriormente citado (Barcelos, 2013), o conflito em torno dos recursos hídricos tende a se agravar, uma vez que o CLIPA será o maior usuário de água de toda a bacia do Rio Paraíba do Sul, o que certamente terá impacto sobre outros usos.

A emergência de tais conflitos evoca questões relativas à justiça ambiental, movimento que defende que os prejuízos decorrentes do modelo de desenvolvimento não afetem desproporcionalmente nenhum grupo social, independentemente de fatores raciais, étnicos ou socioeconômicos.

A literatura situa o surgimento do movimento de justiça ambiental nos EUA a partir da articulação entre movimentos locais que lutavam contra a alocação de aterros e incineradores de resíduos industriais e movimentos por direitos civis (Bullard e Johnson, 2000; Cole e Foster, 2001; Acselrad; Mello e Bezerra, 2009). Bullard e Johnson (2000) destacam neste processo os protestos contra a instalação de um aterro no Condado de Warren, na Carolina do Norte, em 1982. Segundo os autores, as manifestações motivaram estudos de agências estatais sobre a correlação entre a localização de aterros de resíduos perigosos e aspectos raciais e econômicos das comunidades vizinhas. No contexto norte-americano, aspectos raciais e étnicos mostraram-se as variáveis que melhor explicavam a localização das instalações (Bullard e Johnson, 2000; Cole e Foster, 2001).

Apesar da importância da luta dos moradores de Warren e de várias outras comunidades contra a instalação de aterros e incineradores de lixo industrial, a localização de resíduos é apenas um aspecto do movimento, que, segundo Bullard (2000) e Cole e Foster (2001), também se preocupa com a descontaminação de áreas industriais, localização de indústrias poluidoras, exposição diferencial de populações a produtos perigosos, eliminação de riscos ocupacionais, desigual aplicação da legislação ambiental e garantia de representação no processo de tomada de decisão.

Matínez-Alier (1998), em perspectiva semelhante, desenvolve o conceito de ecologismo popular, o qual seria uma via de solução para os conflitos econômico-ecológicos, ao contestar o acesso desigual dos diferentes grupos aos recursos ambientais. Reforçando este aspecto, a Rede Brasileira de Justiça Ambiental (RBJA) expandiu a abrangência do movimento, incluindo entre seus princípios a garantia do "acesso justo e equitativo, direto e indireto, aos recursos ambientais do país" (Acselrad; Mello e Bezerra, 2009). 
Considerando esta questão, é possível perceber que a incorporação de áreas de São João da Barra, ao inviabilizar o uso dos recursos por diversos grupos em favor do grande empreendimento, viola os princípios da justiça ambiental. Por outro lado, o projeto, ao integrar à economia nacional áreas onde o uso do espaço se apresenta de forma predominantemente não capitalista, tem o potencial de aumentar aquilo que Harvey (2006) denominou como acumulação por espoliação ou despossessão, baseado no conceito de acumulação primitiva cunhado por Marx.

Como ressalta Martins (2013:26), “[...] a criação do Complexo do Açu é exemplo dos vários projetos de apropriação do território sendo estabelecidos no país em áreas que, historicamente, não apresentavam atividade econômica voltada para o mercado externo", consistindo em exemplo de como os conflitos locais podem ser determinados por decisões tomadas em outras escalas. De acordo com a teoria de Harvey, a acumulação por espoliação diz respeito à acumulação que ocorre fora dos locais de extração de mais-valia: é a forma de acumulação que ocorre entre o capital e as formas de produção não capitalistas.

Segundo o autor, a acumulação por espoliação é onipresente na história do capitalismo (e não apenas em seu estágio inicial, sob a forma de acumulação primitiva), assumindo maior ou menor relevância em suas diferentes fases e adquirindo maior importância quando ocorrem crises de sobreacumulação. O processo de acumulação por espoliação possui as mesmas características apontadas por Marx na descrição da acumulação primitiva, sejam elas:

[...] a mercantilização e a privatização da terra e a expulsão forçada de populações camponesas; a conversão de diversas formas de direito de propriedade - comum, coletiva, estatal etc. - em direitos de propriedade exclusivos; a supressão do direito aos bens comuns; a transformação da força de trabalho em mercadoria e a supressão de formas de produção e consumo alternativos, incluindo os recursos naturais; a monetarização das trocas e a arrecadação de impostos, particularmente da terra; o tráfico de escravos; e a usura, a dívida pública e, finalmente, o sistema de crédito. (Harvey, 2006:109)

O autor ressalta, ainda, a importância do Estado na viabilização de tal processo. $\mathrm{O}$ conceito parece, então, dar conta dos processos de incorporação de novas áreas à economia nacional, que vem ocorrendo com o emprego de violência e expulsão de populações que fazem usos não capitalistas de tais espaços. Ao que parece, no Brasil, o resgate de um projeto de desenvolvimento orquestrado pelo Estado e a partir das necessidades de reprodução ampliada de capital (doméstico e externo) vem gerando ondas de acumulação por espoliação através de ajustes espaciais internos, processo ilustrado pelo avanço da exploração capitalista 
sobre áreas da Amazônia, terras indígenas, unidades de conservação e ambientes ecologicamente frágeis. Brandão (2010:55) ressalta a marcante "capacidade de interiorização e ‘saída para dentro' que o capitalismo brasileiro aprendeu a utilizar, constituindo cadeias longas e complexas de adição de valor econômico e circuitos mercantis internos vigorosos". A viabilização de tal projeto pressupõe, finalmente, a desregulamentação e flexibilização da legislação ambiental, permitindo o uso econômico de áreas antes destinadas a outros usos, bem como a agilização da concessão de licenças ambientais para empreendimentos tidos como estratégicos para o desenvolvimento do país.

\section{Considerações finais}

A partir do debate apresentado, é possível identificar no CLIPA a eclosão de conflitos ambientais que podem ser considerados "glocais" nos termos de Swyngedouw (2004), isto é, conflitos que emergem como reflexo de um duplo processo de reescalonamento. Por um lado, reescalonamento ascendente para a escala global, ou seja, que remete à circulação global de mercadorias e aos interesses do capital transnacional. Neste sentido, o projeto pode ser observado sob a ótica do provimento de infraestrutura como forma de atração de capital, ou seja, como estratégia do empreendedorismo local (Harvey, 2005; Vainer, 2007).

Por outro lado, diz respeito ao reescalonamento descendente da escala de regulação para níveis locais. Neste âmbito, os capitais privados ou elites de crescimento locais, associados ao poder público estadual, em especial ao Instituto Estadual do Ambiente (INEA) e à CODIN, puderam reconstruir o ambiente jurídico-institucional necessário à viabilização do projeto. $^{15}$

Como exemplo, é possível citar os decretos estaduais que declararam de utilidade pública, para fins de desapropriação em favor da CODIN, a área onde foi prevista a instalação do DISJB. A estes, soma-se o Decreto no 42.422/10, o qual delega à Companhia

[...] poderes específicos para a propositura, em nome próprio, das ações de desapropriação [...] necessárias para a implantação do Distrito Industrial de São João da Barra, autorizando-se, inclusive, o pedido de urgência com vistas à imissão provisória na posse dos mesmos, bem como a adoção de quaisquer outras medidas judiciais ou extrajudiciais que envolvam a

\footnotetext{
15 Informações detalhadas acerca das críticas e ações judiciais que contestam o licenciamento ambiental fragmentado dos empreendimentos do CLIPA e a atuação da CODIN estão descritas no Mapa de Conflitos Envolvendo Injustiça Ambiental e Saúde no Brasil (FIOCRUZ/FASE, 2013).
} 
implantação do Distrito Industrial de São João da Barra. (RIO DE JANEIRO, 2010)

O mesmo instrumento autoriza, ainda, a CODIN a "buscar acordos amigáveis antes ou após a propositura das ações de desapropriação" (Ibid.). A possibilidade de tratamento caso a caso levantada pelo decreto leva a uma despolitização do processo que, no lugar da negociação e elaboração de alternativas coletivas, busca reorientar a regulação para a escala do corpo individual, para usar a expressão empregada por Swyngedouw (2004).

Aqui, vale lembrar as denúncias do uso de violência física na desapropriação de terras, denunciadas pela Associação dos Proprietários de Imóveis e Moradores de Pipeiras, Barcelos, Cajueiro e Campo da Praia - ASPRIM (Barcelos, 2013), por Pedlowski (2012) e pela Associação de Geógrafos Brasileiros - AGB. Tal processo parece estar de pleno acordo com a constatação de Swyngedouw (1996a; 2000a; 2000b; apud Swyngedouw, 2004:41) segundo a qual a "glocalização ou o reescalonamento territorial das formas institucionais levam a aparatos (quasi)estatais mais autocráticos, antidemocráticos e autoritários”.

No caso em debate, a CODIN recebe, através da descentralização de atribuições do Governo do Estado do Rio de Janeiro, inúmeras prerrogativas de uma agência pública, ao mesmo tempo em que estabelece termo de cooperação técnica com o ente empresarial responsável pelo empreendimento, confundindo-se os interesses público e privado.

Nesse contexto, é fundamental considerar a dimensão político-institucional da conversão de áreas e bens públicos ou coletivos em privados (cf. Harvey, 2006) no centro da estratégia de desenvolvimento econômico brasileira em geral e, através de infraestruturas portuárias, em particular. Assim, para além dos processos aqui identificados como "glocais", não deixa de ter importância a escala de regulação nacional neste processo, inclusive através da viabilização de infraestruturas portuárias privadas mediante o lançamento do novo marco legal do setor.

Faz-se necessária, ainda, uma reflexão sobre as mudanças de propriedade e controle dos empreendimentos do grupo EBX. Se, por um lado, o reescalonamento descendente facilitou a viabilização do empreendimento, tendo importância no processo tanto as relações que ocorrem nesse nível quanto a construção da imagem de Eike Batista como empreendedor de sucesso, em escala nacional; por outro, o desenvolvimento subsequente do empreendimento possibilitou que o controle do CLIPA, bem como de outros empreendimentos do grupo, fosse transferido para o capital internacional. Em síntese, observa-se, desde 2007: (i) o início da instalação de uma infraestrutura portuária privada não 
admitida pela legislação nacional previamente à aprovação da nova Lei dos Portos (Lei $\mathrm{n}^{\circ}$ 12.815/2013); (ii) a ação do Estado na viabilização da licença ambiental e do reassentamento da população rural que vivia na área do empreendimento; e, (iii) por último, a transferência do controle acionário do empreendimento para uma empresa multinacional.

De modo geral, transferências de controle desse tipo tendem a provocar, em grande medida, a repatriação de lucros, afetando negativa e diretamente a Balança de Transações Correntes $^{16}$ e, de modo indireto, o Balanço de Pagamentos e a economia nacional como um todo. Além disso, o deslocamento do controle de investimentos econômicos estratégicos possibilita que determinadas decisões a eles relacionadas sejam tomadas de acordo com interesses públicos e privados exógenos, correspondendo a estratégias de acesso a recursos naturais escassos.

Não é possível afirmar, com o escopo da pesquisa realizada, que tal processo tenha sido intencional. Todavia, é importante atentar para seus resultados, que se repetem em outros empreendimentos do grupo EBX, como é possível perceber pela breve descrição dos processos de transferência de controle acionário ao longo do ano de 2013 (cf. item quatro deste artigo). São exemplares dessa orientação os empreendimentos no setor de energia da MPX, agora sob controle alemão na empresa ENEVA; a exploração de minério de ferro em Conceição do Mato Dentro (MG), transferida para a mineradora britânica Anglo American (assim como parte do Projeto Minas-Rio); a venda do porto Sudeste para capitais holandês e árabe; e a passagem do controle da empresa de logística responsável pelo CLIPA para as mãos da norte-americana EIG.

Sobre essa última transação, vale, ainda, destacar a importância atribuída ao empreendimento pelos compradores, devida à localização próxima à Bacia de Campos e à possibilidade de exportação do petróleo extraído do pré-sal (conjunto de rochas localizadas em águas ultraprofundas, abaixo da camada de sal) pelo Porto de São João da Barra. No período de negociações, a agência de notícias Reuters ressaltou o potencial de o pré-sal transformar o Brasil no terceiro maior exportador de petróleo do mundo, depois de Arábia Saudita e Rússia. Segundo jornalistas da agência, uma pessoa próxima ao fundo de investimentos EIG teria afirmado que o interesse no porto era decorrente deste ser "o ponto de desembarque [e consequente reembarque] para todo esse petróleo [...]. É a joia da coroa" (Reuters, 2013c).

${ }^{16}$ As "remessas de renda [lucro] de capitais estrangeiros e as receitas auferidas pelos capitais nacionais no exterior" são contabilizadas no Balanço de Rendas ou Conta de Rendas, uma das três contas do Balanço de Transações Correntes, que compõe o Balanço de Pagamentos (Feijó et al., 2003:162). 
Assim, embora não seja possível aferir a intencionalidade do processo, vale indagar se a construção da imagem do grande empresário nacional não teria facilitado, a partir de elementos de poder e discurso legitimadores, a efetivação de projetos indutores de múltiplos conflitos ambientais, dos quais o CLIPA é expressivo. Nesse caso, em especial, a LLX, tendo se encarregado das primeiras fases da implantação do empreendimento - que envolvem processos de negociação complexos com o Estado e intensa crítica social -, acabou desempenhando um papel funcional para o acesso da EIG/Prumo Logística a uma infraestrutura que lhe confere posição de destaque no transporte transoceânico de commodities - particularmente de petróleo -, controlando a "joia da coroa" do novo sistema portuário brasileiro.

\section{Bibliografia}

ACSELRAD, H. As práticas espaciais e o campo dos conflitos ambientais. In: Conflitos Ambientais no Brasil. Rio de Janeiro: Relume Dumará, Fundação Henrich Boll, 2004. pp. 13-35.

ACSELRAD, H.; MELLO, C. C. A.; BEZERRA, G. N. O que é Justiça Ambiental. Rio de Janeiro: Garamond, 2009. 160p.

ASSOCIAÇÃO DOS GEÓGRAFOS BRASILEIROS - AGB, GRUPO DE TRABALHO EM ASSUNTOS AGRÁRIOS. Relatório dos Impactos Socioambientais do Complexo Industrial-Portuário do Açu. 2011. 57 p.

ANTAQ. Panorama Aquaviário, vol. 06, 2011. Disponível em http://www.antaq.gov.br/. Acesso em: março/2013.

BARCELOS, E. (Coord.). O Projeto Minas-Rio e seus impactos socioambientais: olhares desde a perspectiva dos atingidos. In: ENCONTRO DE INTERCÂMBIO DAS COMUNIDADES EM RESISTÊNCIA AO PROJETO MINAS-RIO. Belo Horizonte; Rio de Janeiro, 2013.

BARRETO, N. M. S.; QUINTO JUNIOR, L. P. A (re)produção do espaço capitalista nas áreas de grandes empreendimentos: uma análise comparativa entre os conflitos socioambientais nos Complexos Portuários do Açu e de Suape. Boletim do 
Observatório Ambiental Alberto Ribeiro Lamego, Campos dos Goytacazes/RJ, vol. 6, n. 1, pp. 57-67, 2012.

BRANDÃO, C. Desenvolvimento, territórios e escalas espaciais - Levar na devida conta as contribuições da economia política e da geografia crítica para construir a abordagem interdisciplinar. In: RIBEIRO, M. T. F.; MILANI, C. R. S. (orgs.). Compreendendo a complexidade socioespacial contemporânea: o território como categoria de diálogo interdisciplinar [online]. Salvador: EDUFBA, 2009. pp. 150-185.

- Acumulação Primitiva Permanente e desenvolvimento capitalista no Brasil Contemporâneo. In: BERNO DE ALMEIDA et al. Capitalismo Globalizado e Recursos Territoriais: fronteiras de acumulação no Brasil contemporâneo. Rio de Janeiro: Lamparina, 2010.

BRESSER-PEREIRA, L. C. O novo desenvolvimentismo e a ortodoxia convencional. São Paulo em Perspectiva, vol. 20, n. 3, pp. 5-24, São Paulo: Fundação Seade, 2006.

BULLARD, R. D.; JOHNSON, G. S. Environmental Justice: Grassroots Activism and Its Impact on Public Policy Decision Making. Journal of Social Issues, vol. 56, n. 3, pp. 555-578, 2000.

CASTRO, I. E. O problema da escala. In: CASTRO, I. E.; GOMES, P. C. C.; CORRÊA, R. L. (orgs.). Geografia: conceitos e temas. Rio de Janeiro: Bertrand Brasil, 2008.

CASTRO, S. M.; ALMEIDA, J. R. Dragagem e conflitos ambientais em portos clássicos e modernos: uma revisão. Soc. \& Nat., Uberlândia, ano 24, n. 3, pp. 519-534, 2012.

COLE, L. W.; FOSTER, S. R. From the Ground Up: Environmental Racism and the Rise of the Environmental Justice Movement. New York University Press, 2001. 243 p.

CUNHA, I. Conflito ambiental em águas costeiras: Relação porto-cidade no Canal de São Sebastião. Ambiente \& Sociedade, vol. VI, n. 2, 2003.

Fronteiras da gestão: os conflitos ambientais das atividades portuárias. RAP Rio de Janeiro, vol. 40, n. 6, pp. 1019-40, 2006.

DE NEGRI, F.; ALVARENGA, G. V. A primarização da pauta de exportações no Brasil: ainda um dilema. Radar - Tecnologia, produção e comércio exterior, n. 13, pp. 7-14, IPEA, 2011. 
DICKEN, P. et al. Chains and networks, territories and scales: towards a relational framework for analyzing the global economy. Global Networks, pp. 89-112, 2001.

ECOLOGUS ENGENHARIA CONSULTIVA/AGRAR. RIMA - Relatório de Impacto Ambiental. Infraestruturas do Distrito Industrial de São João da Barra, s/d.

Exame. Principais pontos das MP 595, que muda concessões de portos. 1/03/2013 (a). Disponível em: http://exame.abril.com.br/ Acesso em: março/2013.

Exame. Os 7 erros de Eike Batista na queda do grupo EBX. 24/07/2013 (b). Disponível em: http://exame.abril.com.br/ Acesso em: março/2014.

FEIJÓ, C. A. et al. Contabilidade Social: o novo sistema de contas nacionais do Brasil. Rio de Janeiro: Elsevier, 2003.

FERNANDES, A. C. Da reestruturação corporativa à competição entre cidades: lições urbanas sobre os ajustes de interesses globais e locais no capitalismo contemporâneo. Espaço e Debates n. 41, Ano xvii, pp. 26-45, 2001.

FIOCRUZ/FASE. Mapa de Conflitos Envolvendo Injustiça Ambiental e Saúde no Brasil, 2013. Disponível em: www.conflitoambiental.icict.fiocruz.br/

Folha de São Paulo. Eike acerta venda de LLX por R\$ 1,3 bilhão. 15/08/2013.

FREITAS, B. V.; OLIVEIRA, E. L. Impactos socioeconômicos da construção do CLIPA sobre a população e o território de São João da Barra. Revista de Geografia, vol. 2, n. 1, pp. 1-10, 2012.

G1. Salinização da água em São João da Barra prejudica produção agrícola. 28/01/2013. Disponível em: http://g1.globo.com. Acesso em: agosto/2013.

GOVERNO FEDERAL. Programa de Aceleração do Crescimento (PAC) - 2007-2010. Material para Imprensa. s/d. Disponível em: http://www.fazenda.gov.br/

HARVEY, D. Do Administrativismo ao Empreendedorismo: a transformação da governança urbana no capitalismo tardio. In: A Produção Capitalista do Espaço. São Paulo: Annablume, 2005. 252p.

HARVEY, D. O "Novo” Imperialismo: acumulação por espoliação. In: PANITCH, L.; LEYS, C. Socialist Regiter: o novo desafio imperial. Buenos Aires: editora CLACSO, 2006. $280 \mathrm{p}$. 
INSTITUTO SOCIOAMBEINTAL - ISA. Mineração em terras indígenas na Amazônia Brasileira. 2013.

KURTZ, H. Scale frames and counter-scale frames: constructing the problem of environmental justice. Political Geography, vol. 22, issue 8, pp. 887-916, nov. 2003.

KURY; K. A., REZENDE, C. E.; PEDLOWSKI, M. A. O entendimento da população de São João da Barra sobre a influência do mega-empreendimento do Complexo Portuário e Industrial do Açu em seu cotidiano. In: V ENCONTRO NACIONAL DA ANPPAS, 2010 .

LLX. http://www.llx.com.br, 2013. Acesso em: agosto/2013.

MARTINEZ-ALIER, J. Da Economia Ecológica ao Ecologismo Popular. Blumenau: EDIFURB, 1998. 362p.

MARTINS, G. R. Disputas por legitimidade em torno dos grandes projetos de investimento: uma análise do processo de criação do Superporto do Açu em São João da Barra - RJ. Dissertação de mestrado, IPPUR/UFRJ, 2013.

MINISTÉRIO DO DESENVOLVIMENTO, INDÚSTRIA E COMÉRCIO EXTERIOR. Exportação Brasileira dos Setores Industriais por Intensidade Tecnológica. Disponível em: http://www.desenvolvimento.gov.br/. Acesso em: março/2013.

MONIÉ, F.; VIDAL, S. M. Cidades, portos e cidades portuárias na era da integração produtiva. RAP Rio de Janeiro, vol. 40, n. 6, pp. 975-95, 2006.

$O$ Globo. Gargalos nos portos provocam 'apagão da soja'. Rio de Janeiro, 21/03/2013. Disponível em: http://oglobo.globo.com/economia. Acesso em: abril/2013.

PEDLOWSKI, M. Complexo do Açu e a exportação de commodities. Entrevista especial IHU online, 2012. Disponível em: < http://www.ihu.unisinos.br/entrevistas/507639exportacao-de-commodities-continuaremos-vivendo-como-se-nunca-tivessemos-saidodo-seculo-xvi-entrevista-especial-com-marcos-pedlowski>. Acesso em: abril/2013.

PÉREZ, M. S.; GONÇALVES, C. U. Desenvolvimento e conflito territorial - primeiras reflexões sobre as comunidades atingidas pelo Complexo Industrial Portuário de SUAPE-PE, Brasil. Revista de Geografia (UFPE), vol. 29, n. 2, pp. 166-179, 2012. 
PRUMO LOGÍSTICA. O empreendimento. 2014a. Disponível em: $<$ http://www.prumologistica.com.br/pt/superporto-do-acu/Paginas/oempreendimento.aspx>. Acesso em: abril/2014.

PRUMO LOGÍSTICA. Clientes e parceiros. 2014b. Disponível em: $<$ http://www.prumologistica.com.br/pt/superporto-do-acu/Paginas/clientes-eparceiros.aspx> . Acesso em: abril/2014.

QUINTO JUNIOR, L. P.; COUTINHO, R. R. Avaliação da sustentabilidade ambiental do entorno do Complexo Portuário Industrial do Açu. Bitacora vol. 2, n. 19, pp. 9-20, 2011.

RANGEL, L. C.; QUINTO JUNIOR, L. P. O Complexo Logístico Industrial Portuário do Açu e os Impactos na Estruturação Urbana e Regional no Norte-Fluminense. In: VI ENCONTRO NACIONAL DA ANPPAS, 2012.

Reuters. Shares of Brazil's EBX Group companies battered by bad News. 15/08/2013 (a).

Reuters. Batista's Brazil miner MMX says seeks partners, asset sales. 15/08/2013 (b).

Reuters. EIG may bid for more of Brazilian Batista's troubled EBX group; by Jennifer Ablan and Jeb Blount. 19/08/2013 (c).

Reuters. Brazilian oil firm OGX presses Batista for cash; shares soar; by Sabrina Lorenzi and Reese Ewing. 06/09/2013 (d).

RIO DE JANEIRO. Decreto 42.422/10. Diário Oficial do Estado do Rio de Janeiro. Ano XXXVI, n. 73, 2010.

SICSÚ, J.; DE PAULA, L. F.; MICHEL, R. Por que novo-desenvolvimentismo? Revista de Economia Política, vol. 27, n. 4 (108), pp. 507-524, 2007.

SOUZA, T. N.; TERRA, R. P.; OLIVEIRA, V. P. S. Implantação do Complexo Portuário do Açu e atividades de pesca artesanal marinha do Norte Fluminense: um conflito socioambiental. Boletim do Observatório Ambiental Alberto Ribeiro Lamego, Campos dos Goytacazes/RJ, vol. 3, n. 2, pp. 23-30, 2009.

SUAPE. Balanço: SUAPE comemora os avanços em 2012. 2012. Disponível em: <http://www.suape.pe.gov.br/news/matLer.php?id=144>. Acesso em: agosto/2013. 
SWYNGEDOUW, E. Globalisation or 'glocalisation'? Networks, territories and rescaling. Cambridge Review of International Affairs, vol. 17, n. 1, pp. 25-48, 2004.

VAINER, C. As escalas do poder e o poder das escalas: o que pode o poder local? Cadernos IPPUR. Ano XV, n. 2, pp. 13-32, 2001.

VAINER, C. Planejamento Territorial e Projeto Nacional: os desafios da fragmentação. Revista Brasileira de Estudos Urbanos e Regionais, vol. 9, n. 1, 2007.

WEISS, L. Globalization and the Myth of the Powerless State. New Left Review n. 225, pp. 327, 1997.

ZBOROWSKI, M. B.; LOUREIRO, C. F. B. Conflitos Ambientais na Baía de Sepetiba: o caso dos pescadores artesanais frente ao processo de implantação do complexo siderúrgico da Companhia Siderúrgica do Atlântico - ThyssenKrupp CSA. In: IV ENCONTRO NACIONAL DA ANPPAS. Brasília: 2008. 